Research Article

\title{
A comparative study of thiamine with metformin on fasting blood glucose of diabetic albino rats
}

\author{
Subhankar Choudhury*, Bhulan Prasad Loc, Rati Ranjan Debbarma, Arijit Das
}

\begin{abstract}
Department of Pharmacology and Therapeutics, Rajendra Institute of Medical Sciences, Ranchi, Jharkhand, India

Received: 28 May 2016 Accepted: 01 July 2016

\section{*Correspondence to:}

Dr. Subhankar Choudhury, Email: dr.subhankar1985@ gmail.com
\end{abstract}

Copyright: (C) the author(s), publisher and licensee Medip Academy. This is an openaccess article distributed under the terms of the Creative Commons Attribution NonCommercial License, which permits unrestricted noncommercial use, distribution, and reproduction in any medium, provided the original work is properly cited.

\begin{abstract}
Background: Thiamine is a member of the vitamin B family. Thiamine is necessary for normal insulin synthesis and secretion. In diabetes thiamine and its derivative benfotiamine showed promising results in prevention of microvascular complications. Some experimental and clinical studies have shown the antihyperglycaemic effect of thiamine. This study compared the antihyperglycaemic effect of thiamine with metformin in streptozotocinnicotinamide induced diabetic albino rats.

Methods: 24 albino rats were taken and divided into four groups of six rats in each group. The groups were normal control, diabetic control, diabetic rats treated with thiamine, diabetic rats treated with metformin. Diabetes was induced in three groups by intraperitoneal injection of Streptozotocin in the dose of $60 \mathrm{mg} / \mathrm{kg}$. To have an ideal type 2 diabetes model nicotinamide was administered $120 \mathrm{mg} / \mathrm{kg}$ intraperitoneally fifteen minutes before streptozotocin administration. After successful induction of diabetes thiamine and metformin were given to the respective group for a period of 6 weeks. Fasting blood glucose was estimated on day $0,7,14,21,28,35,42$ of treatment.

Results: In this study both thiamine and metformin showed significant antihyperglycaemic effect $(\mathrm{p}<0.05)$. Further studies are needed to evaluate and compare the antihyperglycaemic effect of thiamine with other established anti diabetic drugs.

Conclusions: From this study we concluded that individually both thiamine and metformin were effective in controlling hyperglycaemia but metformin was better in achieving normal mean FBS. Further studies are required to validate the antihyperglycaemic effect of thiamine. Study taking different doses of thiamine or with increasing the duration of study period can elaborate the role of thiamine in achieving proper glycemic control.
\end{abstract}

Keywords: Thiamine, Diabetes mellitus, Streptozotocin, Fasting blood glucose

\section{INTRODUCTION}

Diabetes mellitus refers to a group of common metabolic disorders that share the phenotype of hyperglycaemia. Various distinct types of DM are caused by a complex interaction of genetics and environmental factors. Depending on the aetiology of DM factors contributing to hyperglycaemia include reduced insulin secretion, decreased glucose utilization, and increased glucose production. When fully expressed diabetes is characterized by fasting hyperglycaemia. The effects of diabetes mellitus include long term damage, dysfunction and failure of various organs especially heart, kidneys, eyes and blood vessels. Diabetes may present with characteristic symptoms such as thirst, polyurea, blurring of vision, polyphagia, and weight loss and in its most severe form diabetic ketoacidosis and non ketotic hyperosmolar state, which in absence of effective intervention lead to stupor, coma and death. ${ }^{1}$

At present, India is considered as the diabetic capital of the world by WHO. There are approximately 3.5 crore diabetics in India, and this figure is expected to increase up to 5.2 crore by 2025 . Every fifth patient visiting a consulting physician is a diabetic. By the year 2025 it is predicted that India will have a rise of 59 percent of diabetics in the population - which is the highest number of diabetic patients in the world. ${ }^{2}$ 
The maximum cases of diabetes are of type 2 diabetes. The drugs available for treatment are sulfonylureas, biguanides, thiazolidinediones, GLP-1 analogs, gliptins, alfa glucosidase inhibitors, SGLT-2 inhibitors and amylin analogs. Sulfonylureas act by stimulating insulin release from pancreatic beta cells. There is secondary failure and tachyphylaxis to the drugs following prolonged use. Hypoglycaemia, cholestatic jaundice, agranulocytosis, generalized hypersensitivity and dermatological reactions are other disadvantages. Metformin is the first line therapy in type 2 diabetes as it improves peripheral insulin utilization and prevents long term complications of diabetes. But gastrointestinal side effects, contraindication in liver disease, megaloblastic anaemia and lactic acidosis are the inevitable drawbacks. Among the glitazones troglitazone is out of market for its known hepatotoxicity. Rosiglitazone increases the incidence of MI. The only available pioglitazone also carries the risk of macular oedema, bladder cancer and hepatotoxicity in long term use. Alfa glucosidase inhibitors and incretins are used as an adjuvant to others. ${ }^{3}$

Thiamine is a member of the B-vitamin family and was the first water-soluble vitamin to be discovered in 1912 and isolated in $1926 .{ }^{4}$ Thiamine diphosphate is essential for carbohydrate metabolism as it is the co-factor of transketolase in pentose phosphate pathway and dehydrogenases in glycolysis and creb's cycle. ${ }^{4}$ Thiamine is necessary for normal insulin synthesis and secretion. ${ }^{5}$ In the thiamine-deficient state glucose undergoes metabolism via alternate pathways which can result in insulin resistance and complications. ${ }^{6,7}$ In 1987, Dr Saito from Japan found decreased plasma thiamine in patients with diabetes. Thornalley and his team in 2007 proved the glucose induced down regulation of thiamine transporter in proximal tubular epithelial cells leading to decreased renal uptake and excess urinary loss of thiamine. ${ }^{8}$ This deficiency cannot be replenished by therapeutic low dose of thiamine as in lower dose the absorption of thiamine is dependent on these transporters which are already defective. This can be corrected by giving high dose of thiamine as in higher concentration thiamine can pass any biological membrane by passive diffusion. ${ }^{9}$ In experimental and clinical diabetes high dose thiamine therapy not only corrected thiamine loss but also disposed excess glucose via pentose phosphate pathway and revert fasting hyperglycemia. ${ }^{10}$ High dose thiamine also lowered blood glucose in normal individuals after maximal aerobic exercise. ${ }^{11}$ On this background the aims and objectives of this research work was to study the effect of thiamine on fasting blood glucose of non-diabetic and streptozotocin-nicotinamide induced diabetic albino rats.

The objective of this study was to study the effect of thiamine on fasting blood glucose of diabetic albino rats. And to compare the effect of thiamine with metformin on fasting blood glucose of diabetic albino rats.

\section{METHODS}

The entire experiment was carried out in "department of pharmacology and therapeutics, Rajendra Institute of Medical Sciences, Ranchi". The whole experiment was conducted in accordance with ethical norms approved by Institutional Animal Ethics Committee (IAEC), Ranchi, Jharkhand, India. Healthy male Wister rats weighing between 150-250 gms were taken for the present study. The animals were kept in clean and dry cages with 12:12 hours light-dark cycle at room temperature and humidity. They were acclimatized to the available housing condition for 2 weeks and were fed with standard laboratory diet consisting of soaked black gram (Kala Chana) and water was given ad libitum. Arrangements were made to ensure regular cleaning of cages and disposal of excreta and urine. The cages were floored with a layer of saw dust for absorption of urine of rats. This was done because after induction of diabetes there would be excess of urination of rats.

\section{Drugs used were}

- Thiamine hydrochloride $100 \mathrm{mg}$ tablet (TIM 100), Gentech Healthcare Pvt Ltd.

- Metformin $500 \mathrm{mg}$ tablet (Glycomet), US Vitamins Limited.

- Streptozotocin $250 \mathrm{mg}$ powder, HIMEDIA, Mumbai

- Nicotinamide 100 gm powder Animed, Kolkata

\section{Selection criteria for animals}

- All the animals used for the study were healthy and active in their cage.

- Animals were male wistar rats.

- Weight of the animals used was 150-250 grams.

- Fasting blood sugar before the initiation of study was within the range of $200-250 \mathrm{mg} / \mathrm{dl}$.

\section{Methodology}

Study animals were divided into four groups with six animals in each group. One group consisted non diabetic rats and other three groups had hyperglycaemic rats with fasting blood glucose $200-250 \mathrm{mg} / \mathrm{dl}$. In the three diabetic groups the rats were randomly distributed. Rats were given different treatment orally once daily for 42 days in the morning hour at 09:30-10:30 am.

- Group A rats were non diabetic and served as a normal control and were given $0.9 \%$ normal saline

- Group B rats were diabetic and were given $0.9 \%$ normal saline. They served as diabetic control

- Group C rats were diabetic and treated with thiamine (10 mg/200 gm body weight, p.o.)

- Group D rats were diabetic and treated with metformin ( $9 \mathrm{mg} / 200 \mathrm{gm}$ body weight, p.o.) 


\section{Estimation of fasting blood glucose}

Rats were kept deprived of food overnight and were allowed free access to water. Blood samples were collected from the tail vein of rats and fasting blood glucose was measured with the help of glucometer before the induction of diabetes as well as on day $0,7,14,21$, 28,35 and 42 of the study.

\section{Statistical analysis}

Data entry was done on MS Excel and "SPSS version 20" software was used for data analysis. One-way ANOVA test was used to compare the effect of the drugs on different groups. Tukey's honestly significant difference test was used for post hoc analysis of significant overall differences.

\section{RESULTS}

Table no 1 shows the mean and standard deviation of fasting blood glucose in all groups from day ' 0 ' - day '42'.

Table 2 compares the fasting blood glucose of group 3 and 4 with group 1 . There is significant decrease in fasting blood glucose in thiamine and metformin treated groups. Metformin decreased blood glucose faster than thiamine and mean difference with group 1 was insignificant on day ' 35 ' $(p>0.05)$. On the other thiamine has given similar result on day $42(\mathrm{p}>0.05)$.

Table 1: Fasting blood glucose in all groups from day ' 0 ' - day ' 42 '.

\begin{tabular}{|lllll|}
\hline $\begin{array}{l}\text { Fasting blood } \\
\text { glucose }\end{array}$ & $\begin{array}{l}\text { Normal control } \\
\text { (group 1) }\end{array}$ & $\begin{array}{l}\text { Diabetic control } \\
\text { (group 2) }\end{array}$ & $\begin{array}{l}\text { Diabetic with thiamine } \\
\text { (group 3) }\end{array}$ & $\begin{array}{l}\text { Diabetic with metformin } \\
\text { (group 4) }\end{array}$ \\
\hline Day 0 & $82.00 \pm 2.61$ & Mean \pm SD & Mean \pm SD & Mean \pm SD \\
\hline Day 7 & $80.83 \pm 4.02$ & $215.33 \pm 8.48$ & $213.50 \pm 7.99$ & $216.17 \pm 7.14$ \\
\hline Day 14 & $80.33 \pm 2.42$ & $236.67 \pm 7.62$ & $192.33 \pm 6.98$ & $183.00 \pm 8.79$ \\
\hline Day 21 & $83.33 \pm 4.89$ & $249.83 \pm 7.57$ & $172.83 \pm 4.26$ & $147.83 \pm 7.03$ \\
\hline Day 28 & $83.33 \pm 3.93$ & $259.83 \pm 7.89$ & $154.83 \pm 4.02$ & $128.67 \pm 6.59$ \\
\hline Day 35 & $82.17 \pm 2.79$ & $272.33 \pm 8.14$ & $110.67 \pm 4.50$ & $106.83 \pm 6.80$ \\
\hline Day 42 & $80.83 \pm 4.49$ & $284.17 \pm 7.08$ & $87.67 \pm 2.25$ & $84.67 \pm 1.63$ \\
\hline
\end{tabular}

Table 2: Comparing FBS of group 1 with group 3 and 4.

\begin{tabular}{|c|c|c|c|}
\hline \multirow{2}{*}{\multicolumn{2}{|c|}{ Fasting blood glucose }} & \multicolumn{2}{|c|}{ Normal Control } \\
\hline & & \multirow{2}{*}{$\begin{array}{l}\text { Diabetic with thiamine } \\
-131.500^{*}\end{array}$} & \multirow{2}{*}{$\begin{array}{l}\text { Diabetic with metformin } \\
-134.167^{*}\end{array}$} \\
\hline \multirow{3}{*}{ Day 0} & Mean difference & & \\
\hline & Std. Error & 3.433 & 3.103 \\
\hline & $\mathrm{P}$ value & $<0.001$ & $<0.001$ \\
\hline \multirow{3}{*}{ Day 7} & Mean difference & $-111.500^{*}$ & $-102.167^{*}$ \\
\hline & Std. Error & 3.287 & 3.945 \\
\hline & $\mathrm{P}$ value & $<0.001$ & $<0.001$ \\
\hline \multirow{3}{*}{ Day 14} & Mean difference & $-92.500^{*}$ & $-67.500^{*}$ \\
\hline & Std. Error & 2.001 & 3.034 \\
\hline & $\mathrm{P}$ value & $<0.001$ & $<0.001$ \\
\hline \multirow{3}{*}{ Day 21} & Mean difference & $-71.500^{*}$ & $-45.333^{*}$ \\
\hline & Std. Error & 2.583 & 3.35 \\
\hline & $\mathrm{P}$ value & $<0.001$ & $<0.001$ \\
\hline \multirow{3}{*}{ Day 28} & Mean difference & $-53.333^{*}$ & $-23.500^{*}$ \\
\hline & Std. Error & 2.44 & 3.205 \\
\hline & $\mathrm{P}$ value & $<0.001$ & 0.001 \\
\hline \multirow{3}{*}{ Day 35} & Mean difference & $-28.167^{*}$ & -2.5 \\
\hline & Std. Error & 1.899 & 1.319 \\
\hline & $P$ value & $<0.001$ & 0.628 \\
\hline \multirow{3}{*}{ Day 42} & Mean difference & -6.833 & -3.833 \\
\hline & Std. Error & 2.051 & 2.162 \\
\hline & $\mathrm{P}$ value & 0.111 & 0.696 \\
\hline
\end{tabular}


Table 3: Comparing FBS of group 2 with group 3 and 4.

\begin{tabular}{|c|c|c|c|}
\hline \multirow{2}{*}{\multicolumn{2}{|c|}{ Fasting blood glucose }} & \multicolumn{2}{|c|}{ Diabetic control } \\
\hline & & Diabetic with thiamine & Diabetic with metformin \\
\hline \multirow{3}{*}{ Day 0} & Mean difference & 1.833 & -0.833 \\
\hline & Std. Error & 4.757 & 4.525 \\
\hline & $\mathrm{P}$ value & 1.000 & 1.000 \\
\hline \multirow{3}{*}{ Day 7} & Mean difference & $34.667^{*}$ & $44.000^{*}$ \\
\hline & Std. Error & 4.216 & 4.747 \\
\hline & $\mathrm{P}$ value & $<0.001$ & $<0.001$ \\
\hline \multirow{3}{*}{ Day 14} & Mean difference & $63.833^{*}$ & $88.833^{*}$ \\
\hline & Std. Error & 3.426 & 4.116 \\
\hline & $\mathrm{P}$ value & $<0.001$ & $<0.001$ \\
\hline \multirow{3}{*}{ Day 21} & Mean difference & $95.000^{*}$ & $121.167^{*}$ \\
\hline & Std. Error & 3.501 & 4.099 \\
\hline & $P$ value & $<0.001$ & $<0.001$ \\
\hline \multirow{3}{*}{ Day 28} & Mean difference & $123.167^{*}$ & $153.000^{*}$ \\
\hline & Std. Error & 3.707 & 4.249 \\
\hline & $\mathrm{P}$ value & $<0.001$ & $<0.001$ \\
\hline \multirow{3}{*}{ Day 35} & Mean difference & $162.000^{*}$ & $187.667^{*}$ \\
\hline & Std. Error & 3.655 & 3.39 \\
\hline & $P$ value & $<0.001$ & $<0.001$ \\
\hline \multirow{3}{*}{ Day 42} & Mean difference & $196.500^{*}$ & $199.500^{*}$ \\
\hline & Std. Error & 3.034 & 3.11 \\
\hline & $\mathrm{P}$ value & $<0.001$ & $<0.001$ \\
\hline
\end{tabular}

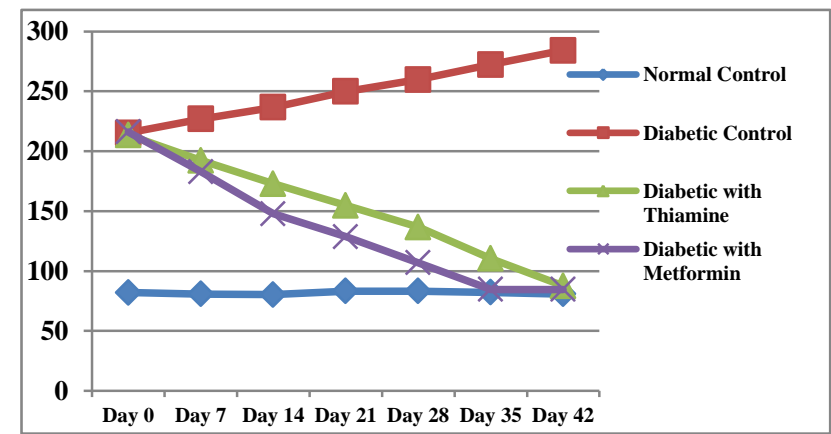

Figure 1: FBS among all groups throughout study period.

Table 3 compares the fasting blood glucose of group 2 with group 3 and 4 . There is significant decrease blood glucose in group 3 and $4(\mathrm{p}<0.05)$.

Figure 1 shows that the green line of thiamine treated group merges with the blue line of group 1 on day 42 . The violet line of metformin already merged with group 1 on day 35 . In group 2 the red line remained far away from other three lines indicates the increase in mean fasting blood glucose throughout the study.

\section{DISCUSSION}

Accumulation of triosephosphates arising from high cytosolic glucose concentrations in hyperglycaemia is one likely or potential trigger for biochemical dysfunction implicated in signalling for polyol, hexosamine, protein kinase $\mathrm{C}$ and AGE pathway by the liver leading to insulin resistance and development of diabetic complications. ${ }^{6}$ This may be prevented by disposal of excess triosephosphates via the reductive pentose phosphate pathway. ${ }^{7}$ Thiamine is the co-factor of transketolase in pentose phosphate pathway and in high doses it increases the activity of this enzyme leading to disposal of excess cytosolic glucose. ${ }^{16}$ The products of pentose phosphate pathway are non-harmful to cell. On the other hand the decreased flux through hexosamine and protein kinase $\mathrm{C}$ pathway decreases glycosylation of glucose transporters. This may lead to enhanced insulin action and may decrease blood glucose. ${ }^{17}$ Sadek KM et al with his group showed that high dose thiamine $(50 \mathrm{mg} / \mathrm{kg})$ had no effect on fasting blood glucose of non-diabetic albino rats but revert fasting hyperglycaemia of diabetic albino rats. ${ }^{14}$ Pandhiani et al also showed that thiamine decreased post prandial blood glucose in diabetic rats but had no effect on non-diabetic albino rats. ${ }^{18}$ Gonzalez-Ortiz et al showed that high dose thiamine therapy (600 mg/day) for one month significantly decreased fasting blood glucose in diabetic individuals. ${ }^{19}$

In this study a model of type 2 diabetes was produced by streptozotocin and nicotinamide. Thiamine and metformin were administered in diabetic rats to see the effect on fasting blood glucose. The results are showing that thiamine and metformin both significantly decreased 
fasting blood glucose throughout the study period. On day 42 the antihyperglycaemic effect of thiamine was similar like metformin. But the decline in blood glucose was more rapid with metformin. By achieving normal mean fasting blood glucose on day 35 metformin was found superior.

With previous studies our study also established the antihyperglycaemic property of thiamine. Metformin is the first line oral antihyperglycemic drug approved for treatment of type 2 diabetes. But in higher doses metformin have some demerits like gastrointestinal upset, vitamin B12 deficiency and lactic acidosis. On the other hand thiamine was found extremely safe in higher doses. ${ }^{20}$

\section{CONCLUSION}

The present animal study was a small study as the number of animals, the dose, and duration of the study was also fixed. Study taking higher doses of thiamine with large no of animals or with increasing the duration of study period may further focus on its effectiveness in achieving proper glycemic control.

Funding: No funding sources

Conflict of interest: None declared

Ethical approval: The study was approved by the Institutional Ethics Committee

\section{REFERENCES}

1. Zimmet P. Preventing diabetic complications: a primary care perspective. Diabetes Res Clin Pract. 2009;84:107-16.

2. Raheja BS, Kapur A, Bhoraskar A, Sathe SR, Jorgensen LN, Moorthi SR, et al. Diab Care Asia: India Study: diabetes care in India - current status. J Assoc Physicians India. 2001;49:717-22.

3. Goodman Gillman. Insulin, Oral Hypoglycaemic agents and the pharmacology of endocrine pancreas. The Pharmacological Basis of Therapeutics Eleventh Edition. 2006;60:1686-10.

4. Gubler CJ, Thiamine, Handbook of Vitamins: Nutritional, Biochemical, and Clinical Aspects (L. J. Machlin, ed.), Marcel Dekker, New York; 1984:233.

5. Rathanaswami P, Pourany A, Sundaresan R. Effects of thiamine deficiency on the secretion of insulin and the metabolism of glucose in isolated rat pancreatic islets. Biochem Int. 1991;25(3):577-83.

6. Brownlee M. Biochemistry and molecular cell biology of diabetic complications. Nature. 2001;414:813-20.

7. Hammes HP, Du X, Edelstein D. Thiamine and benfotiamine blocks three major pathways of hyperglycaemic damage and prevents experimental diabetic retinopathy. Nat Med. 2003;9:294-99.

8. Larkin JR, Thornalley PJ. High glucose causes a decrease in expression of thiamine transporters in human proximal tubule epithelial cells in vitro. Diabetologia. 2008;51:219.

9. Hoyumpa AM, Strickland R, Sheehan JJ, Yarborough G, Nichols S. Dual system of intestinal thiamine transport in humans. J Lab Clin Med. 1982;99(5):701-8.

10. Thornalley PJ, BJ R, Karachalias N, Rabbani N. Prevention of decline in glycaemic control in streptozocin-induced diabetic rats by thiamine but not by Benfotiamine. Diabet Med. 2010;27(1):74.

11. Mehdi JRK, Reza KH, Saba M, Kamilia M. Effect of supplementary consumption vitamin B1 (thiamine) on blood glucose changes during and after maximal aerobic exercise. ISSN. 2013;3(7):195-201.

12. Mohan C. Calbiochem buffers. A guide for the preparation and use of buffers in biological systems. 2014;1:17-22.

13. Nayak. Antidiabetic activity of benzopyrone analogues in nicotinamide-streptozotocin induced type 2 diabetes in rats. The Scientific World Journal Volume. 2014;2014:854267.

14. Sadek KM, Taha N, Korshom M, Mandour A. Thiamine ameliorate hepatic, renal dysfunction and dyslipidemia in diabetic rats. Journal of current research in science. 2013;1(1):35-9.

15. Rao AS. Pharmacological screening methods and toxicology. First edition. 2014;1:42-56.

16. Pacal L, Tomandl J, Svojanovsky J, Krusova D, Stepankova S, Rehorova J, et al. Role of thiamine status and genetic variability in transketolase and other pentose phosphate cycle enzymes in the progression of diabetic nephropathy. Nephrol Dial Transplant. 2011;26(4):1229-36.

17. Beltramo E, Berrone E, Tarallo S, Porta M. Effects of thiamine and benfotiamine on intracellular glucose metabolism and relevance in the prevention of diabetic complications. Acta Diabetol. 2008;45:13141.

18. Pandhiani MB. Effect of thiamine on glycemic control in induced diabetic rat model. Journal of current research in science. 2013;1(1):68-74.

19. Gonzalez-Ortiz M, Martinez-Abundis E, RoblesCervantes JA, Ramirez-Ramirez V, Ramos-Zavala MG. Effect of thiamine administration on metabolic profile, cytokines and inflammatory markers in drugnaive patients with type 2 diabetes. Eur $\mathrm{J}$ Nutr. 2011;50:145-9.

20. Smithline HA, Donnino M, Greenblatt DJ. Pharmacokinetics of high-dose oral thiamine hydrochloride in healthy subjects. BMC Clinical Pharmacology. 2012;12:4.

Cite this article as: Choudhury S, Loc BP, Debbarma RR, Das A. A comparative study of thiamine with metformin on fasting blood glucose of diabetic albino rats. Int J Basic Clin Pharmacol 2016:5:1539-43. 